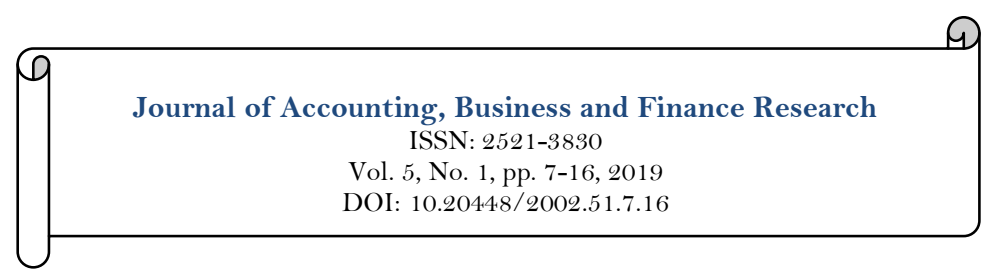

$\checkmark$ updates

\title{
A Literature Review of the Research on Markups of China's Manufacturing Exports and Non- Export Firms
}

\author{
Yanfen Wang ${ }^{1}$ \\ 'Doctoral student. School of Economics, Central University of Finance and Economics, Beijing, China. \\ Email:dahaiwangyanfen@163.com
}

\begin{tabular}{l|l}
\multicolumn{3}{|c}{ Abstract } & \\
According to the variable markup trade theory and the industrial & Keywords: \\
organizational theory, generally higher markup means stronger market & Export firm \\
pricing power and higher productivity for a firm, while higher-productivity & Variable markup \\
firms choose to export, which means the markup of export firms should be & Export max rebate \\
higher. However mod & Importcompetition \\
of non-export firms is even higher. Therefore, scholars, who have observed & Resource allocation. \\
this problem, have begun to use different markup-measurement methods to & JEL Classification: \\
study this phenomenon, ranging from different angles, which include export & F19. \\
tax rebates, import competition, and resource allocation. This paper reviews & \\
the literature from four aspects, which are the development of the variable & Licensed: \\
markup trade theory, the development of markup measurement methods, the & This work is licensed under a \\
development of empirical research on China export firms' abnormal markup & Creative Commons Attribution 4.0 \\
phenomenon, and looks forward to the follow-up research, in order to make & License. \\
some contribution to continuously supplement and improve the research about & Publisher: \\
this abnormal phenomenon in China. & Scientific Publishing Institute
\end{tabular}

Funding: This study received no specific financial support.

Competing Interests: The author declares that there are no conflicts of interests regarding the publication of this paper.

\section{Introduction}

Markup $^{1}$ is an indicator to measure the deviation between product price and marginal cost, equals to the ratio of product price to marginal price. That Product price equals marginal cost is the perfect embodiment of effective resource allocation under the framework of perfect competition in traditional economics, but incomplete competition, that product price deviates from marginal cost is closer to economic reality. As early as 1934 , A.P. Lerner proposed the Lerner index. ${ }^{2}$ By measuring the degree of deviation between the two, the market power of the firm is measured. Today, markup is defined as the ratio of product price to marginal cost. It is often used to measure a company's monopoly power or trade gains, and is also concerned by industrial organization theory and Heterogeneous Firm Trade Theory.

The marriage of international trade theory with markup comes from the New Trade Theory, which was initiated by economists represented by Krugman in the late 1970s, with increasing returns and incompleteness. To study international trade issues with competition as a basic assumption, then economists completed the integration of international trade theory with the theory of industrial organization, and since

\footnotetext{
${ }^{1}$ The markup calculation formula is defined as $m k p=\frac{P}{M C}$, where mkp is the markup, $\mathrm{P}$ is the market price, and MC is the marginal cost.

${ }^{2}$ The Lerner index calculation formula is defined as $\mathrm{L}=\frac{P-M C}{P}$

equal to 1 or even negative. A larger value means that the market power is stronger, 1 means complete monopoly, and o means perfect competition.
} 
then the concept of markup was introduced to international trade theory. However, it is the New-New Trade Theory begins the in-depth and systematic discussion of the markup, especially the Heterogeneous Firm Trade Theory, which has developed strongly in recent years. The variable markup theory makes markup endogenous, and studies trade firms and trade gains from the markup of endogenous changes, which opens up a new dimension for international trade research.

Since China's accession to the WTO, a large number of trade companies have emerged. What are their performances? What are their market pricing powers and what is their productivity? Markup is a key indicator for measuring firm productivity and market power, and it is a hit with China. So far, the variable markup theory has been widely used to study the behaviour and performance of Chinese companies exposed to the world trade environment. We have found an interesting phenomenon. The markup of Chinese export firms is generally lower than that of non-export companies, this is contrary to trade theory. The two propositions of Heterogeneous Firm Trade Theory, which are the selection effect and the promotion of competition effect, tell us that firms with high productivity will choose to export, while those with lower productivity will withdraw from the international market, thereby promoting competition and optimizing the allocation of resources. The high markup means stronger market pricing power and higher productivity, which means that the markup of export companies should be higher. In response to the current situation of resource mismatch, domestic scholars try to explore the answers from different angles. This paper will summarize these studies, explore the deficiencies of existing research, and explore new research directions.

In summary, the following structure is arranged as follows: The second part is to sort out the theoretical evolution process of the introduction of variable markup to trade theory and the process of making markup endogenous in Heterogeneous Firm Trade Theory. The third part sorts out the current measurement variable markup, and compares three mainstream methods, finally tells the advantages and disadvantages of each method. The fourth part summarizes the research results of the market pricing power of export and nonexport firms and trade gains applying variable markup theory, especially those empirical studies on the markup deficit of Chinese manufacturing export and non-export firms; the last part points out the expandable research direction and more rigorous research methods based on the summary and review of the literature; the sixth part is the general conclusion.

\section{The Evolution Process of Variable Markup Theory}

(1) Heterogeneous Firm Trade Theory with constant markup

The New Trade Theory model and the earliest Heterogeneous Firm Trade Theory assume that the markup is exogenous, the classic imperfect competition model such as Krugman (1980) and the improved Ricardo model of Eaton and Kortum (2002), (The famous EK model), and Melitz (2003) Heterogeneous Firm Trade Theory, all use the CES (Constant elasticity of substitution) utility function, the expression of the CES utility function is:

$$
\mathrm{U}=\left[\int_{\omega \in \Omega} q(\omega)^{\rho} d \omega\right]^{1 / \rho}
$$

Introduced by Dixit and Stiglitz (1977) for the first time in the framework of a monopolistic competition model, where collections $\Omega$ Represents a collection of products to choose, the product is replaceable, and the elasticity of substitution for any two items is $\sigma=\frac{1}{(1-\rho)}>1(0<\rho<1)$, under general equilibrium $p=\frac{\sigma}{\sigma-1} w b$, where $\mathrm{b}$ is the marginal input per unit of product produced, and $\mathrm{w}$ is the price of one unit input, so $\mathrm{MC}=\mathrm{wb}, m k p=\frac{P}{M C}=\frac{\sigma}{\sigma-1}$.It can be seen that the markup is constant, that is to say, the setting of the constant marginal alternative ultimately determines that the markup is exogenous. Of course, this kind of setting is unreasonable, it is not in line with the fact that the company has a variable markup, and it is impossible to measure the pricing power of the firm, and it is impossible to measure the trade gain reflected by the variable markup.

\section{(2) Empirical study on the markup of the 1980s-1990s trade liberalization or integration area}

Before theoretical economists have generally made markup be endogenous to trade theory, other economists have observed the variable markup phenomena in the international trade environment through empirical study. Trade policy reforms in many emerging countries in the 1990 s provided economists a research pool of natural experimental data.

Levinsohn (1993) used the firm-level data after Turkey strode on the road of trade liberalization in the 1980s, and empirically tested that the firm markup under the level of imperfect competition fell after the trade opened, but it would be Strengthening and upgrading because of trade protection policies such as tariffs and quotas. Pravin and Devashish (1998) empirically studied India's trade gains. In 1991, India severely released trade freedom by reducing tariffs on imported goods and properly restraining quotas. This literature also used firm-level data. The econometric analysis shows that the markup of the firm has decreased after the trade open 
policy. Harald (2007) used the panel data of the 10 member states of the European Union from 1981-1999 to study the impact of the EU unified market on the markup of firms. The promotion of trade integration has a structural effect. For example, the markup in the manufacturing sector has dropped significantly, but in the service sector, it has been rising since the early 1990 s.

\section{(3) The advent and development of the theory of variable markup model}

In view of the fact that the markup of the firm is inherently variable, the theory of heterogeneous firm trade has evolved from a different perspective towards the endogenous and variable markup in the end of this century. Unlike the Melitz model of the invariant markup, the variable markup model internalizes the markup into the heterogeneous firm model by changing the utility function and the demand function. Such models include the MO model (Melitz \& Ottaviano, 2008) the AB model Atkeson and Burstein (2008), Edmond, Midrigan, and $\mathrm{Xu}$ (2015), Feenstra and Weinstein (2017), and the ACDR model (Arkolakis, Costinot, \& Donaldson, 2019).

Among them, the MO model introduces endogenous variable markups by using the quasi-linear preference of product-level differences (the demand function of Ottaviano, Tabuchi, and Thisse (2002) combines with the differences in the productivity of the firm, and further more makes the competitive viscosity endogenous. The AB model uses the Nested CES demand system to construct the variable markup under oligopoly competition. The ACDR model embeds the VES (Variable Elasticity of Substitution) demand system into the monopolistic competition framework. Feenstra and Weinstein (2017) endogenous markup is achieved by using translog preferences.

The common feature of these theoretical literatures is that by changing and constructing different demand structures and market structures, the markup under the incomplete competitive price mechanism is endogenously variable. To analyse the firm's pricing behaviour through the variable markup, and explore another perspective to analyse trade benefits, that is the markup decline caused by the promotion of the procompetitive effect. According to the variable markup model theory, the markup and productivity of an firm are endogenous, and the two are positively related. A higher rate of markup means higher productivity. The increase in trade freedom will expose the company into a higher-intensity competitive environment, only companies with higher productivity will choose to export, and they can compete with the international market with a relatively high rate of markup. More variable space of the markup means greater competitiveness.

\section{The Measurement Methods of Markup}

The calculation method of the markup is classified into two types: the accounting method and the production function method. The accounting method is to directly calculate the markup through the accounting index, and the production function method is to find the elasticity of firm's output through the firm production function and then to obtain the markup. Accounting methods have been widely used because of their simplicity and directness. The production function method is currently the most widely used in the literature, mainly (De Loecker \& Warzynski, 2012) method and Edmond et al. (2015) method. Both the production function method and the accounting method require the intermediate input or industrial added value data of the firm.

\section{(1) Accounting method}

Domowitz, Hubbard, and Petersen (1986) concluded that most of prior scholars to construct price-cost margin $(\mathrm{PCM})$ as:

$$
P C M=\frac{\text { Value of Sales }- \text { Payroll }- \text { Cost of Materials }}{\text { Value of Sales }}
$$

obviously, $\mathrm{PCM}=\frac{P-M C}{P}$, wages and material costs refer to intermediate inputs, but with regard to sales value, Domowitz et al. (1986) pointed out that sales value will differ from industrial added value because of changes in inventory, so the construction method is biased, they reconstruct PCM as:

$$
P C M=\frac{\text { Value of Sales }+\Delta \text { Inventories }- \text { Payroll }- \text { Cost of Materials }}{\text { Value of Sales }+\Delta \text { Inventories }}
$$

since $\mathrm{PCM}=\frac{P-M C}{P}$, wages and material costs refer to intermediate inputs, while sales value and inventory changes represent industrial added value, then we can summarize the accounting method as follows:

$$
\frac{P-M C}{P}=1-\frac{1}{m k p}=\frac{v a-p r}{v a+n c m}
$$

Among them, as mentioned above, $\mathrm{mkp}(\mathrm{p} / \mathrm{mc})$ represents the markup, va represents the industrial added value, $\mathrm{pr}$ is the total wage paid, ncm refers to the net intermediate input factor cost, va, pr and ncm are all statistical values within a specified statistical period. 


\section{(2) Production function method}

The use of the production function method to calculate the markup can be traced back to Hall (1989). Hall (1989) builds the basic framework through maximizing the manufacturer's profit according to the optimal solution conditions with output elasticity and factor input. The basic framework becomes the benchmark model of the production function method. Later, Wooldridge (2009) and other scholars used the IV and GMM methods to optimize the problem of the estimation error caused by the unpredictable factors of the benchmark model due to the lack of control variables. The De Loecker and Warzynski (2012) method and the Edmond et al. (2015) method described below are the most sophisticated methods that have been explored on the basis of the former.

\section{a. De Loecker and Warzynski (2012) method}

De Loecker and Warzynski (2012) basic measurement framework was constructed from Hall (1989) and referenced (Klette, 1999) and other literature on industry markup research perspectives, drawing on the control variable approach in Olley and Pakes (1996). Markup is directly derived using firm-level output data without relying on any demand structure or market structure assumptions. The core of the method is to solve the markup calculation formula by minimizing the manufacturer's cost.

The first step is to set the production function of firm $i$ at time $t$ as:

$$
Q_{i t}=Q_{i t}\left(X_{i t, \ldots,}^{1} X_{i t}^{V}, K_{i t}, \omega_{i t}\right)
$$

Among them, companies need $v$ inputs (such as labor, intermediate inputs, electricity, etc.) to carry out production, and $\mathrm{k}$ represents capital investment. $\omega$ represents productivity, in addition, here requiring $Q(\cdot)$ Continuous and second order differentiable for all parameters. Producers minimize production costs, then the Lagrangian equation is as follows:

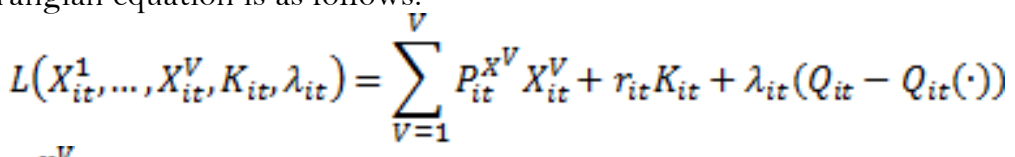

$P_{i t}^{X^{V}}$ representatives the price of $X^{V}$ input, $r_{i t}$ represents the price of capital $\mathrm{k}$, make the Lagrange equation $X_{\text {it }}^{V}$ derivation, solve the optimization problem, get follows:

$$
\frac{\partial L_{i t}}{\partial X_{i t}^{V}}=P_{i t}^{X^{V}}-\lambda_{i t} \frac{\partial Q_{i t}(\cdot)}{\partial X_{i t}^{V}}=0
$$

Move the term, multiply both sides of the equation by $\frac{x_{i t}^{V}}{Q_{\text {it }}}$, get follows:

$$
\frac{\partial Q_{i t}(\cdot)}{\partial X_{i t}^{V}} \frac{X_{i t}^{V}}{Q_{i t}}=\frac{1}{\lambda_{i t}} \frac{P_{i t}^{X^{V}} X_{i t}^{V}}{Q_{i t}}
$$

Among them, $\lambda_{i t}=P_{i t}^{X^{V}} \frac{\partial x_{i t}^{V}}{\partial Q_{i t}(-)}$, the input price multiplied by the marginal input (also is the marginal cost), so $\lambda_{i t}=M C$. Give $\mu_{i t}=\frac{P_{i t}}{\lambda_{i t}}, P_{i t}$ is the price of the commodity (output), $\mu_{i t}$ is the markup $\left(m k p_{i t}\right)$. Give $\theta_{i t}^{X}=\frac{\partial Q_{i t}(\cdot) X_{i t}^{V}}{\partial x_{i t}^{V}}, \theta_{i t}^{X}$ is the elasticity of output, get follows:

$$
\theta_{i t}^{X}=\mu_{i t} \frac{P_{i t}^{X^{V}} X_{i t}^{V}}{P_{i t} Q_{i t}}
$$

Give $\alpha_{i t}^{X}=\frac{p_{i t}^{X} X_{i t}^{V}}{P_{i t} Q_{i t}}, \alpha_{i t}^{X}$ represents the ratio of the intermediate input value to the total output value, which gives:

$$
\mu_{i t}=\theta_{i t}^{X}\left(\alpha_{i t}^{X}\right)^{-1}
$$

It can be seen that the key to the measurement markup is to estimate the output elasticity. The estimation of output elasticity depends on the production function. The most common case is to set the production function to translog production function, then to estimates the specific production function with firm datas, which in turn calculates the output elasticity, and finally estimates the markup.

\section{b. Edmond et al. (2015) method}

The basic framework of the Edmond et al. (2015) model comes from the AB model (Atkeson \& Burstein, 2008) and the producers studied in the $\mathrm{AB}$ model are intermediate input producers in two symmetrical national trade markets, downstream end-product manufacturers are faced with a completely competitive pattern, producing homogeneous products, and need to obtain production factors from the continuous intermediate goods industry, while the intermediate products producers in the industry are limited, so the 
intermediate products manufacturers are facing the oligarchy competition environment of cournot model, the elasticity of demand of producers is decreasing in a closed oligopolistic competition environment, so the markup is increasing. However, international competition can reduce the market share of oligopolistic manufacturers and thus lower the markup. The Edmond et al. (2015) model captures the linear relationship between market share and markup under the framework, and derives the estimated formula for markup.

The Edmond et al. (2015) model sets the production function of the intermediate product manufacturer in the domestic market as the Cobb-Douglas production function. Under the constraint condition, the first-order derivative solves the problem of maximizing the profit of the manufacturer, and the optimized condition is derived to derive the markup relationship about labor, labor expenditure, total output value, and output elasticity:

$$
\frac{W_{t} l_{i t}}{p_{i t} y_{i t}}=\frac{1-\alpha}{m k p_{i t}}
$$

$W_{t}$ is the wage level of the $\mathrm{t}$ period, $l_{i t}$ is the number of employees employed by i company during the $\mathrm{t}$ period, $p_{i t}$ is the market price of the products produced by the company i, $y_{i t}$ is the total output of the firm i, $\alpha$ represents the output elasticity of labor, $m k p_{i t}$ is the markup.

\section{(3) Applicability and Limitations of Three Methods}

a. Accounting Method

The biggest advantage of accounting margins is that it is simple and straightforward, fast in calculation, and low requirements about data. However, it is also tired of these "advantages". Due to the simple principle behind it, it is considered to rough. First, the accounting method is applicable to the case where the scale return is constant and the factor cost is constant. Second, Bresnahan (1987) pointed out that the accounting method is not unique. Different accounting rules correspond to different fixed costs and intermediate inputs, then the accounting method's markup achievements are not unique. It can be said that there is no stable economic significance between the markup and the accounting indicators. Finally, accounting method is also easier to ignore factors such as economic cycles and external shocks. However, accounting method is still being used, indicating that in some scenarios, its use value is still very large.

Martin (2002) comprehensively discussed the pros and cons of accounting method, and the empirical results show that accounting method can still provide some more intuitive and useful information relative to other measurement methods. Siotis (2003) used the production function method and accounting method to estimate the markup when measuring the industry markup of Spain from 1983 to 1996, and compared the measured values of the two methods through the correlation test. The calculated values are highly correlated, and the markup value calculated by the accounting method can better highlight the differences between large industries.

Sheng and Wang (2012) used the accounting method to calculate the markup when studying the problem of low pricing of Chinese export firms. They believed that the database period cited in the article was too short, in order to avoid the impact of economic cycles and external shocks. It is more reasonable to adopt accounting method. Qian, Pan, and Mao (2015) study how the export tax rebate affects the markup of the firm and causes the resource to be misplaced. They used the same data source as Sheng and Wang (2012) so the accounting method is used as the same reason.

\section{b. De Loecker and Warzynski (2012) Method}

The DWL method is currently the most widely used in the field of markup research. Especially in the past two years, the domestic research on the direction of markup, the DWL method is widely used no matter from which point of view and which direction.

Zhu, Zhong, and Li (2018) used the DWL method to study the markup of multi-product export firms, and considered that the DWL method solved the problem of unobservable input of product elements. $\mathrm{Li}$ and $\mathrm{Xu}$ (2018) studied Markup and financing constraints of manufacturing firms through DWL method. Liu and Duan (2018) use the DWL method to measure the markup, and then examine the relationship between markup and legal environment and contract intensity. Cao, Huang, Sun, and Sun (2018) Study the impact of the Asian Free Trade Area on China's minimum wage and firm markup using the DWL method to estimate the markup. Shen and Xiang (2017) use the DWL method to test the industrial aggregation externality from the perspective of markup. Song and Zhu (2017) use the DWL method to study the impact of China's foreign anti-dumping policy on markup.

The DWL method has been recognized by many scholars, mainly because the economic theory of the DWL method is relatively solid, which largely relaxes the conditional constraints on the market structure and the demand structure, and can directly estimate the output elasticity through different production functions of different firms.

Although the DWL method is rigorous, the requirements for data are relatively high. When estimating the production function, the product price and output quantity at the firm level are required. There are not many databases that can record this level on a global scale. Therefore, many scholars are based on existing 
Estimates of income data and industry average price data, although to some extent the data information has been complemented, there will inevitably be biased in the estimation.

c. Edmond et al. (2015) Method

The application of the Edmond et al. (2015) method is not as general and in-depth as the DWL method, mainly because the Edmond et al. (2015) method is derived from a specific model framework. First, the method is framed by the oligopolistic market. Second, the method relies more on the role of labor factors in production input, so the universality is worse. At present, in the domestic literature, Qian, Fan, and Huang (2016) explored and used the method of Edmond et al. (2015) which is considered to be very suitable for studying Chinese problems.

Qian et al. (2016) used this method for three reasons. First, compared to the DWL method, the data required by Edmond et al. (2015) method can be directly obtained from the Chinese industrial firm database. Second, Compared to the production function method, the Edmond et al. (2015) method is more focused on calculating the total wages of firms in the total industrial output value, and the long-term comparative advantage of China's manufacturing industry is mainly reflected in the labor factor, so Qian et al. (2016) thinks that this method is more suitable for China's national conditions. Finally, Edmond et al. (2015) method is derived based on the Cournot oligopoly model under the AB model, Qian et al. (2016) think that China's manufacturing export firms' high concentration is consistent with the oligopolistic market structure, so they believe that using Edmond et al. (2015) method to measure the cost of Chinese manufacturing firms is effective and more realistic. However, although China's labor resources are abundant, it usually takes a long time to dismiss laborers. Especially for state-owned firms, labor input is usually not freely adjustable, so Qian et al. (2016) use labor input as a variable to estimate, which would lead the estimated markup of the firm still be biased.

\section{Empirical Study on the Markup of Export Firms and Non-Export Firms}

Sheng and Wang (2012) used the micro data of Chinese industrial firms from 1999 to 2007 to explore the mystery of Chinese firms' low export prices. First of all, the article empirically tests the markup gap between China's manufacturing export firms and non-export firms. It turns out that the markup of export firms is generally lower than that of non-export firms, which is contrary to the conclusion of the variable markup theory. Because according to the theoretical guidance, in the free trade scenario, the choice of export should be the firm with higher productivity and higher variable markup. Therefore, the article further points out that the reason for this situation comes from the export tax rebate and the excessive competition because of the biased export structure relied on the labor-intensive industry. However, the indicator for measuring export subsidies is the accounting indicator of non-operating income, and there is a large statistical error with the actual subsidy amount, so the empirical result is greatly discounted.

Qian et al. (2016) studied the impact of import competition on the markup of Chinese manufacturing firms. The data of China Industrial Firm Database from 1999 to 20007 was used. The empirical results show that the impact of export competition to firms' markup is negative. Among them, the competitive pressure brought by the external imported products faced by Chinese firms is measured by the tariffs of imported products and the penetration rate of imported products. The tariff data of WTO is used to match the tariff level of imported goods. This angle is too single. After all, the competitive environment faced by Chinese companies is not only brought about by imported goods, but also the impact of trade policies such as tariff quotas on the competitive environment. It is also necessary to consider the competition among domestic manufacturers, so their research can easily lead to missing variables problems in the empirical model.

The problem to be explained by Ming (2018) is the same as that of Sheng and Wang (2012). It is the mystery of the low price of Chinese exports. It uses the data of the China Industrial Firm Database from 2000 to 2006, but the angle is very different. Ming (2018) returns the essence of Heterogeneous Firm Trade Theory, which is to choose from the perspective of competition effect, selection effect and resource allocation. By measuring competition effect and selection effect, and then returning with markup, test Whether the effect of choice has a greater impact on markup or the effect of competition is greater, that is to say, in the context of resource mismatch, whether the productivity of firms, competition among firms and the level of exit of industries are still as theoretically confirmed playing a role. Finally, it is concluded that the selection effect is still a positive impact on the markup, but is offset by the competitive effect. The biggest problem of Ming (2018) research is that both the competitive effect and the selection effect are indicators that are difficult to observe, even indicators that are more difficult to estimate than the markup. It is not intuitive to analyze the selection effect and the competitive effect through the differential decomposition method. And those effect indicators will change with the decomposition method, especially the same accounting indicators used in the measurement will lead to strong endogenous in the measurement empirical process, so the empirical results are also difficult to avoid some bias.

Qian et al. (2015) expands the variable markup theory model by adding export tax rebate to the M-O model, and theoretically deduced that the export tax rebate has an inhibitory effect on the markup of firms, and adopts 2000-2006 firm data of the China Industrial Firm Database and the export tax rebate data of China 
Customs to empirically test the theory of their extension. However, the empirical part of the paper uses accounting methods to calculate the markup. Without more comparison, it is possible that the calculated markup data will be too rough, and the measurement model is too simple and simplified. Therefore, the expansion space od the empirical research in this literature is still large.

$\mathrm{Yu}$ and Yuan (2016) studied the impact of trade liberalization on markup, and studied the impact of domestic tariff policies and foreign tariff policies on firm markup, and finally found that the decline of foreign tariffs on domestic firms markup is a boost, but the decline in domestic final product tariffs can lead to lower firm markup. However, this document does not explain the difference in the markup between export and nonexport firms, but the overall estimation of the impact of tariff levels on China's overall processing trade.

Chen and Sheng (2017) empirically studied the relationship between global value chain and firm markup. The data is about Chinese manufacturing firms from 2000 to 2006, indicating that Chinese manufacturing firms have joined the global value chain system, which is positively affects the firms' markup.

\section{Research Outlook}

(1) Research prospects based on comprehensively examining the impact of competition pattern on firm markup

Based on these existing representative research results, the follow-up study can cut into the two aspects of the import competition created by import tariffs and the domestic competition created by export subsidies. This angle is different from previous research, which only analyses import competition. Or only analyses domestic competition. Previous studies have not even intuitive tariffs and subsidy data to accurately measure import competition and domestic competition. Therefore, follow-up research needs to examine the mechanisms how competitive affect the markup difference between export and non-export firms more closely and more comprehensively.

The irrational competition pattern leads to the inefficiency of market entry and exit, which leads to resource mismatch, which is ultimately reflected in the reverse difference of markup. However, the competition pattern of domestic manufacturing under international trade is formed both by international competition and domestic trade policy. So follow-up research needs to measure both import competition and domestic competition. The import competition is measured by the penetration rate of imported goods and the level of tariffs, while domestic competition includes the level of tax rebate subsidies and the status of industry survival. These data come from the WTO website, China Customs website and industrial firm database, through data fusion and processing, to form panel data and conduct empirical research.

\section{(2) Research prospects based on the difference in markup between export and non-export firms}

The fourth part of this paper has showed that Sheng and Wang (2012) and Ming (2018) have observed significant differences in the markup of Chinese manufacturing export and non-export firms. According to the existing literature research, this paper adopts Simple and straightforward accounting method, using the firm data of China Industrial Firm Database from 1999 to 2007, directly calculate the markup of each firm, and eliminate the extreme value below 0 above 3. According to the export delivery situation of the firm, to judge whether the firm belongs to the export firm or not, and then upgrade the dimension to the years, industries, provinces and different ownership systems. According to the markup of the average industrial output value of each firm, we can acknowledge the export firms' markup to non-exporting firms.

a. Markup of manufacturing export firms and non-export firms in each year

Since some industrial firm data in 2004 is lacked, such as data of industrial added value and intermediate inputs, the weighted average markup of 2004 is lacking. From 1999 to 2007, the markup of exporting firms has been increasing. Compared with the markup of non-export firms, although the markup is increasing with the passage of the year, the gap between export firms and non-export firms has gradually increased from 0.3 to 0.7. Of course, whether such differences are significant is not, we need to follow up in next study.

b. Markup of manufacturing export firms and non-export firms in each province

The provincial and county codes extracted from the industrial firm database can successfully identify the provinces to which the firms belong. Although the data in 2005-2007 lacks the provincial code information, the database matching can complement the province data of the previous year that lasted until 2005-2007. A total of 31 provinces, municipalities and autonomous regions in the database, except for Guizhou Province, Yunnan Province and Tibet, all other regions have lower export firms than non-export firms.

c. Markup of export firms and non-export firms in different industries

The industry code in the industrial firm database is consistent with the national economic industry classification. The manufacturing industry is intercepted. The big categories of industry in the database are 40, for three-quarters of the manufacturing industry, the markup of Chinese export firms is lower than that of non-export firms. Those industries whose export and non-export firms are slightly equal or higher than nonexport firms are generally some regionally strong resource industries or completely monopolized industries, 
such as mining and smelting, or the industry of water and gas supply. Therefore, it can be seen that the markup abnormal contrast between export and non-export firms also exists in various classified industries.

d. Markup of different ownership export firms and non-export firms

According to the information on the controlling shareholder in the industrial firm database, the controlling nature of the firm can be divided into state-owned holding, collective holding, private holding, Hong Kong, Macao and Taiwanese holding, foreign holding and others. According to this classification, the weighted average export and non-export firms are respectively classified according to this classification. No matter for which type of ownership of the firm, the export firm is lower than the cost of the non-export firm.

e. Research outlook

Regarding the accounting of markup, the third part above details the three methods that are recognized and widely used, but few articles use these three methods simultaneously to calculate and compare the differences. The empirical significance about the markup difference of export and non-export firms has rarely been empirical tested in the past literature. Therefore, in the subsequent research, if these three methods are simultaneously used to calculate the markup and tested which method's advantage and disadvantage with the empirical data of China, then the pros and cons of these three methods are an innovation, taking a deeper step, it is also an innovation to use three sets of data to test the difference in the markup between export and nonexport firms.

(3) Prospects for research based on the status of China's industrial firm database

As can be seen from the third part of this paper, three methods of calculating markup are commonly used in research literature in recent years: Accounting method, De Loecker and Warzynski (2012) method and Edmond et al. (2015) method. All three methods require the intermediate input or industrial added value data of the firm. At present, only the Chinese industrial firm database can provide the data related to the micro-firm intermediate input and industrial added value. The latest Chinese industrial firm database has been updated to 2013, but since 2008, the industrial added value and intermediate input data are no longer included in the database, and industrial added value and intermediate input cannot be calculated through accounting indicators, so for China domestic published research on the markup rate, even the latest published article in the third quarter of 2018 , use data from the industrial firm database closed at 2007.

The Chinese industrial firm database is obtained from the national census statistics of the National Bureau of Statistics. It is used by many scholars to study microeconomic problems, but the database itself also has many problems plaguing researchers. First of all, although the database has data since 1997, the statistical standardization began to be standardized and unified until 1998. Therefore, most researchers use data after 1999. Secondly, the data in 2004 lacks industrial added value. The input and export delivery value directly affect the calculation of the markup for the year. Finally, the company often changes the company name or even the legal person code in different years, so it is necessary to check other registration information and regional information to identify the same company, this directly increases the difficulty of data processing.

As mentioned above, the longest span of research on markups in this direction is the data from 1999-2007. However, China's export tax rebate policy has been undergoing structural changes, and it has gradually favored subsidies for high-tech export industries. It is no longer a flood subsidy, especially since the global financial crisis in 2008, China's export firms have suffered a round of reshuffle in the industry, the surviving trade firms are those survivals of the fittest. Under such a background, is the competitive landscape still excessive competition before 2008? Is the markup of export and non-export firms still a violation of the variable markup theory? If it still violates, then the explanations of Sheng and Wang (2012) have strong historical limitations, which in turn lead to the reversal of export and non-export firms. With the progress of history, it is very likely that the reason for the abnormal markup contrast will no longer be an export tax rebate and labor-intensive export product. If it is no longer violated, is the productivity and cost of Chinese firms ushered in a turning point in this historical period? Is it due to excessively vicious competition?

Therefore, subsequent research can try to pull the timeline to a more recent year and then compare the changes and the current status. Due to the nature of the data of the Chinese industrial firm database, there is no subsequent industrial added value and intermediate input data can be used, but we may use the accounting data released by the listed firm. Because for listed firms all foreign trade business needs to be distinguished from domestic sales, and the sales volume and gross profit margin should be calculated separately. The gross profit margin can be used to approximate the markup rate to expand the longitudinal research.

\section{Conclusion}

The theory of international trade began to introduce the concept of markup from the period of new trade theory in the 1980s. The emerging Heterogeneous Firm Trade Theory internalizes markup into the theoretical model, explains the internal reason why markup changes along with trade environment and the competitive landscape, and demonstrates the role of markup in the selection effect and the promotion of competition. The continuous improvement of the variable markup theory has opened up a new research 
perspective for scholars from various countries to discuss trade gains. At the same time, the method of measuring markup is also progressing, and is committed to being closer to economic reality and less statistical bias. There are rigorous theoretical foundations, and there are many methods of measurement. The research on markup is beginning to be more and more subdivided and deeper and deeper.

In particular, we found that the markup between Chinese manufacturing exporting and non-exporting firms is in a abnormal contrasting relationship, which means that there is a certain degree of mismatching of resources in China's manufacturing market. The problem has been empirical researched in the past several years, but there are defects in comprehensiveness, measurement methods and data span. There is a lot of room for follow-up research. I hope that the follow-up research can study this more comprehensively from the perspective of innovation.

\section{References}

Arkolakis, C., Costinot, A., \& Donaldson, D. (2019). The elusive pro-competitive effects of trade. The Review of Economic Studies, 86(1), 46-80.

Atkeson, A., \& Burstein, A. (2008). Pricing-to-market, trade costs, and international relative prices. American Economic Review, 98(5), 1998-2031.

Bresnahan, T. F. (1987). Competition and collusion in the American automobile industry: The 1955 price war. The Journal of Industrial Economics, 35(4), 457-482.

Cao, L., Huang, H., Sun, Y., \& Sun, Y. (2018). China-ASEAN free trade area, minimum wage and firm markup rate. Journal of Guangxi University of Finance and Economics, 6, 1-23.

Chen, S., \& Sheng, B. (2017). Global value chain, firm heterogeneity and markup of firms. Industrial Economics Research, 4, $1-16$.

De Loecker, J., \& Warzynski, F. (2012). Markups and firm-level export status. American Economic Review, 102(6), 24372471.

Dixit, A. K., \& Stiglitz, J. E. (1977). Monopolistic competition and optimum product diversity. The American Economic Review, 67(3), 297-308.

Domowitz, I., Hubbard, R. G., \& Petersen, B. C. (1986). Business cycles and the relationship between concentration and price-cost margins. The RAND Journal of Economics, 17(1), 1-17.

Eaton, J., \& Kortum, S. (2002). Technology, geography, and trade. Econometrica, 7O(5), 1741-1779.

Edmond, C., Midrigan, V., \& Xu, D. Y. (2015). Competition, markups, and the gains from international trade. American Economic Review, 105(10), $3183-3221$

Feenstra, R. C., \& Weinstein, D. E. (2017). Globalization, markups, and US welfare. Journal of Political Economy, 125(4), $1040-1074$.

Hall, S. G. (1989). Practitioners corner: Maximum likelihood estimation of cointegration vectors: An example of the Johansen procedure. oxford Bulletin of Economics and statistics, 51(2), 213-218.

Harald, B. (2007). Has the EU's single market programme fostered competition? Testing for a decrease in mark-up Ratios in EU Industries. oxford Bulletin of Economics and statistics, 69(4), 497-519.

Klette, T. J. (1999). Market power, scale economies and productivity: estimates from a panel of establishment data. The Journal of Industrial Economics, 47(4), 45 1-476.

Krugman, P. (1980). Scale economies, product differentiation, and the pattern of trade. The American Economic Revierw, $70(5), 950-959$.

Levinsohn, J. (1993). Testing the imports-as-market-discipline hypothesis. Journal of International Economics, 35(1-2), 1-22.

Li, S., \& Xu, B. (2018). Financial marketization, financing constraints and firm markup: Evidence from Chinese manufacturing firms. International Trade Issues, 2, 164-174.

Martin, S. (2002). Advanced industrial economics. Oxford, UK: Blackwell Publishers.

Melitz, M. J. (2003). The impact of trade on intra-industry reallocations and aggregate industry productivity. Econometrica, $71(6), 1695-1725$.

Melitz, M. J., \& Ottaviano, G. I. (2008). Market size, trade, and productivity. The Review of Economic Studies, 75(1), 295316.

Ming, X. (2018). The mystery of the low markup of Chinese export firms and its formation mechanism - based on the perspective of resource allocation. Asia-Pacific Economy, 4, 84-151.

Olley, G. S., \& Pakes, A. (1996). The dynamics of productivity in the telecommunications equipment industry. Econometrica, 64(6), 1263-1297.

Ottaviano, G., Tabuchi, T., \& Thisse, J. F. (2002). Agglomeration and trade revisited. International Economic Review, 43(2), 409-435.

Pravin, K., \& Devashish, M. (1998). Trade liberalization, market discipline and productivity growth: New evidence from India. Journal of Development Economics, 56(2), 447-462.

Qian, X., Fan, D., \& Huang, H. (2016). Import competition and markup of Chinese manufacturing firms. World Economy, 3, $71-94$.

Qian, X., Pan, Y., \& Mao, H. (2015). Export tax rebate, firm markup and resource misplacement. World Economy, 8, 80-106.

Shen, H., \& Xiang, X. (2017). Specialization, related diversification and firm markup-a new perspective to test the externalities of industrial agglomeration. Economics, 10, 81-98.

Sheng, D., \& Wang, Y. (2012). The mystery of Chinese firms' low-cost exports——based on the perspective of firm bonus rate. Management World, 5, 8-23.

Siotis, G. (2003). Competitive pressure and economic integration: An illustration for Spain, 1983-1996. International Journal of Industrial Organization, 21(10), 1435-1459. 
Song, H., \& Zhu, X. (2017). China's foreign anti-dumping and manufacturing firm markup. International Trade Issues, 12, 94-107.

Wooldridge, J. M. (2009). On estimating firm-level production functions using proxy variables to control for unobservables. Economics Letters, 104(3), 112-114.

Yu, M., \& Yuan, D. (2016). Trade liberalization, processing trade and markup - evidence from Chinese manufacturing firms. Management World, 9, 33-43.

Zhu, S., Zhong, T., \& Li, R. (2018). Product trade liberalization of intermediate goods trade and multi-product export firms. China Industrial Economy, 1, 41-59. 